\title{
Rantings of an Associate Editor: A Plea to Manuscript Reviewers
}

$\mathrm{O}$ ver one year ago, when Editor-in-Chief, Mike Gross, asked me to join JASMS as an Associate Editor, I felt honored that he and the other editors would allow me to be part of the team that assembles what I believe to be the top mass spectrometry journal today. However, I had little idea of how much work was involved. Mike and our Managing Editor, Joyce Neff, gave me a rough idea of how many manuscripts I would handle on a monthly basis. It didn't seem to be that much work, but reality quickly set in as the workload started to arrive. It is more work than I expected initially because the number of manuscripts submitted to JASMS has been on a steady rise. That's a great and positive reason to have more work assigned to each of the Associate Editors. It means that people want to publish their work in JASMS and people want to read the articles in JASMS. However, the other reason for the unanticipated workload for Associate Editors is the close attention required for manuscript review. Interactions I have with the manuscript reviewers have been both a pleasure and a burden.

Manuscripts submitted to JASMS are received by the "home office," i.e., Mike and Joyce. These manuscripts are subsequently assigned to one of the Associate Editors for shepherding through the review process. (In the beginning, it was like receiving a gift on Christmas day. Today, it's more like what you see in spy/thriller movies like "Mission Impossible" or the "Bourne" movies, e.g., "A mission has been assigned to you. This message will self-destruct in $5 \mathrm{s.}$.) The next step is to assign at least two reviewers to the manuscript. We scan through the manuscript to select potential reviewers. Suggestions provided by the authors are extremely useful and they can speed the process. Messages are sent to potential reviewers to request their availability and, if they accept the assignment, they are reminded that we would like to receive their comments and recommendations two weeks after receiving the manuscript.

This part of the process was more difficult than I expected. It is difficult to find reviewers with the necessary expertise and the time available to review papers. There are a number of reviewers who have reviewed multiple manuscripts I have assigned during the past year and I am extremely grateful to them. They have made this part of my job very easy. But I realize the enormous burden we place on reviewers when we request their help. Everyone is busy with their "regular" jobs. Certainly, I don't expect that everyone I have requested to review a manuscript would have the time at that moment. (Plea Number One: Please let us know promptly if you cannot review when requested. My feelings won't be hurt if you decline. A prompt response would allow me to select another potential reviewer quickly. Please also suggest other potential reviewers if you decline.) It is wonderful that a number of younger scientists are requesting that they be considered as potential reviewers for JASMS-keep those requests coming!

My most difficult task, however, has been dealing with late reviews. We all want our papers published quickly. In today's electronic era, we can hasten most aspects of the publication process-from distributing manuscripts to reviewers, to producing the printed version of the accepted manuscript, to web-posting the final version. However, there is not much we can do to encourage reviewers to submit critiques more quickly. A significant amount of the total time it takes for a manuscript to be published is spent in the reviewers' hands. For manuscripts I handle, Joyce and/or I will send out friendly reminders if a review is late. A second reminder may be sent after another period of time. I may send out a third more personal and hopefully more persuasive message. Phone calls are my next options. (Plea Number Two: Please respond to our reminders. Let us know if you need extra time. Again, my feelings won't be hurt. If, for some unexpected reason, you cannot complete the assignment, the sooner we know, the sooner we can try to find another reviewer.)

So, what is the incentive to review papers in a timely manner? Well, there are the obvious reasons that you are participating in the overall scientific process and that you are helping to disseminate scientific knowledge-reasons we tell our students. Or, I could remind you of the principle that dates back over 2000 years that you may have learned when you were kids, "Do onto others as you would have others do onto you." Would you want your own manuscript to be read by a tortoise reviewer? Moreover, if you agree to submit your review within two weeks, shouldn't you attempt to take this promise somewhat seriously?

Another incentive to review manuscripts promptly, however, has been less obvious, until now. Did you ever wonder how JASMS Editorial Board members are selected? The Editorial Board provides us feedback and suggestions on how to improve the overall scope and quality of JASMS. Members of the Board are selected not only because they are leaders in our field, but they are also selected based on their record of supporting 
JASMS, as evident from their publication record in JASMS, the numbers of papers they review for JASMS, the quality of their reviews, and how quickly they submit their reviews. I am not aware of other journals in our field using these criteria for Board membership. Selection for a journal Editorial Board looks good on your curriculum vitae because it is evidence of recognition by your peers. It can be especially helpful for job promotion and tenure, if you are in academia.

And if those are not sufficient reasons to entice you to submit your reviews on time, we always reward our
Editorial Board members with a dinner with the JASMS Editors at ASMS conferences and occasionally invite our best reviewers for lunch at the conference. So, please submit reviews promptly and you may be selected to receive fine food and wine, and our delightful, lively company. What more incentive do you need?

Joseph A. Loo Associate Editor Department of Chemistry and Biochemistry UCLA, Los Angeles, California, USA 